\title{
Validation of a food-frequency questionnaire for cohort studies in rural Japan
}

\author{
Keiko Ogawa ${ }^{1}$, Yoshitaka Tsubono ${ }^{1, *}$, Yoshikazu Nishino ${ }^{1}$, Yoko Watanabe ${ }^{1}$, \\ Takayoshi Ohkubo', Takao Watanabe ${ }^{2}$, Haruo Nakatsuka ${ }^{3}$, Nobuko Takahashi ${ }^{4}$, \\ Mieko Kawamura ${ }^{5}$, Ichiro Tsuji ${ }^{1}$ and Shigeru Hisamichi ${ }^{1}$ \\ 'Division of Epidemiology, Department of Public Health and Forensic Medicine, Tohoku University Graduate School \\ of Medicine, 2-1 Seiryo-machi, Aoba-ku, Sendai, Miyagi 980-8575, Japan: ${ }^{2}$ Department of Environmental Health, \\ Miyagi University of Education, Sendai, Japan: ${ }^{3}$ School of Nursing, Miyagi University, Sendai, Japan: ${ }^{4}$ Faculty of \\ Human Sciences, Sendai Shirayuri Women's College, Sendai, Japan: ${ }^{5}$ Faculty of Human Life and Environmental \\ Science, Kochi State Women's University, Sendai, Japan
}

\section{Submitted 13 November 2001: Accepted 20 August 2002}

\begin{abstract}
Objectives: To examine the validity and reproducibility of a self-administered foodfrequency questionnaire (FFQ) used for two cohort studies in Japan.

Design: Cross-sectional study.

Setting: Two rural towns in the Miyagi Prefecture, in north-eastern Japan.

Subjects: Fifty-five men and 58 women.

Results: A 40-item FFQ was administered twice, 1 year apart. In the mean time, four 3-day diet records (DRs) were collected in four seasons within the year. We calculated daily consumption of total energy and 15 nutrients, 40 food items and nine food groups from the FFQs and the DRs. We computed Spearman correlation coefficients between the FFQs and the DRs. With adjustment for age, total energy and deattenuation for measurement error with the DRs, the correlation coefficients for nutrient intakes ranged from 0.25 to 0.58 in men and from 0.30 to 0.69 in women, with median of 0.43 and 0.43 , respectively. Median (range) of the correlation coefficients was $0.35(-0.30$ to 0.72$)$ in men and $0.34(-0.06$ to 0.75$)$ in women for food items and $0.60(-0.10$ to 0.76$)$ and $0.51(0.28-0.70)$ for food groups, respectively. Median (range) of the correlation coefficients for the two FFQs administered 1 year apart was $0.49(0.31-0.71)$ in men and $0.50(0.40-0.64)$ in women for nutrients, 0.43 $(0.14-0.76)$ and $0.45(0.06-0.74)$ respectively for food items, and $0.50(0.30-0.70)$ and $0.57(0.39-0.66)$ respectively for food groups. Relatively higher agreement percentages for intakes of nutrients and food groups with high validity were obtained together with lower complete disagreement percentages.

Conclusions: The FFQ has a high reproducibility and a reasonably good validity, and is useful in assessing the usual intakes of nutrients, foods and food groups among a rural Japanese population.
\end{abstract}

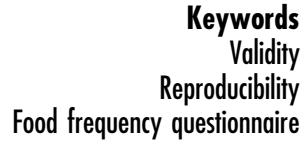

Food-frequency questionnaires (FFQs) have been used in epidemiological studies to investigate the association between diet and chronic diseases ${ }^{1}$. The validity and reproducibility of FFQs in terms of consumption of nutrients has been assessed in variety of studies in Western countries $^{1}$ and Japan $^{2-11}$.

Epidemiological interest may focus on examining the associations between health and individual foods ${ }^{12,13}$ or food groups ${ }^{14-18}$. There are several foods that are eaten frequently in the very localised area of Japan and are hypothesised to have health-protective effects, such as green tea ${ }^{19-22}$ and soy products ${ }^{23-26}$. However, relatively few studies ${ }^{11,27-29}$ have examined the validity and reproducibility of FFQs in terms of the consumption of foods or food groups, especially in non-Western countries.

We employed a self-administered 40-item FFQ for two population-based prospective cohort studies in Miyagi Prefecture, in north-eastern Japan, that were started in $1990^{30}$ and in $1994^{31}$. In the present work, we examined the validity and reproducibility of this questionnaire for total energy and 15 nutrients, 40 food items and nine food groups, using intakes measured by 12 days of diet records as the reference standard. 


\section{Subjects and methods}

\section{Study design and subjects}

The subjects were a sub-sample of participants in one or two of the cohort studies. Fifty-nine men and 60 women were selected on a voluntary basis. Written informed consent was obtained from all subjects. We surveyed the participants with the questionnaire twice, 1 year apart, in November 1996 (FFQ1) and in November 1997 (FFQ2). In the mean time, we collected a total of 12 days of diet records, on three consecutive days (3-day DRs) four times in the year, in November 1996 and February, May and August 1997.

\section{Food-frequency questionnaire}

This FFQ was originally developed for the national collaborative cohort study of cancer in Japan ${ }^{32}$. The questionnaire included 40 food items and supplementary questions about the use of vitamin supplements and milk and sugar in coffee and tea. It was not originally intended to calculate the consumption of nutrients from responses on food frequencies. The questionnaire did not specify the time frame for reporting the consumption of food items and did not query specify portion size information. The questionnaire asked about the average frequency of consumption of each food. Regarding the foods consumed differently between seasons, it asked about the frequency in the season in which they are consumed most frequently within a year. Five frequency categories were used for the majority of food items (almost never, 1-2 days per month, 1-2 days per week, 3-4 days per week, almost every day). For rice and bean paste soup, the number of bowls consumed per day was asked. The frequency of alcohol consumption was asked with five frequency categories (almost never, less than once per week, 1-2 days per week, 3-4 days per week, almost every day) and the usual amount was asked with six categories. For four non-alcohol beverages, we used five categories (almost never, sometimes, 1-2 cups per day, 3-4 cups per day, more than 5 cups per day).

\section{Diet records}

The DRs were collected so as to cover both weekdays and weekends and also four different seasons of the year. We instructed the participants to record all foods and beverages consumed in a standardised booklet. We asked them to provide detailed descriptions of each food (openended) including the weights prepared and proportions consumed. Research dietitians checked their records in a standardised way after completion by the participants.

\section{Statistical analysis}

We excluded six subjects who failed to complete the full 12 days of diet records or the two FFQs, and used the remaining 113 subjects (55 men and 58 women) for subsequent analysis.
We calculated the daily consumption of total energy and 15 nutrient variables from the DRs using the Standard Tables of Food Composition published by the Science and Technology Agency of Japan ${ }^{33}$. Regarding alcohol, we limited the calculation to alcohol consumed as beverages and excluded alcohol used for cooking. For calculation from the FFQs, we developed a food composition table that corresponded to the items listed in the questionnaire. We determined a portion size for each food item based on the median values observed in the DRs, separately for men and women. Finally, we computed daily nutrient intakes by multiplying the consumption frequency of each food by the nutrient content of the assigned portion size and summing these values for all the foods. We did not consider nutrient intakes from vitamin supplements because the prevalence of daily users was low (20 subjects, $17.7 \%$ ).

For calculating the daily consumption of the individual foods from DRs, we summed the amount of all the food codes in the DRs corresponding to the 40 items in the FFQ. We then examined the daily consumption of 40 items from the FFQ by converting the selected frequency category for each food to a daily intake. Daily intakes were calculated by multiplying an average number of daily servings by assigned portion sizes. We calculated the daily consumption of nine food groups by combining the individual food items. The nine food groups are the following: (1) total meats (consisting of four items); (2) dairy products (three items); (3) pulses (three items); (4) total fruits (three items); (5) total fruits and vegetables (nine items); (6) total fruits and vegetables excluding pickles (eight items); (7) total vegetables (six items); (8) total vegetables excluding pickles (five items); and (9) yellow \& green vegetables (three items). We constructed these food group categories based on the availability of food items in the questionnaire and interest in their potential associations with health outcomes; thus the grouping was not necessarily comprehensive to cover the whole variety of food items.

To assess the validity of the FFQ, we first compared the mean daily intakes between the DRs and FFQ2. We then calculated Spearman correlation coefficients (95\% confidence intervals) between the DRs and FFQ2. In addition to crude correlation coefficients, we computed coefficients with adjustment for age and total energy intake by the residual method ${ }^{34}$ and with correction for measurement error (within-person variation) in the 12-day DRs ${ }^{35}$. We also calculated Spearman correlation coefficients between the two FFQs (FFQ1 and FFQ2) to assess the 1-year reproducibility.

Second, we divided the daily intakes from DRs into thirds and compared them with thirds calculated from the FFQ, expressing the results as agreement, adjacent agreement and complete disagreement percentages. We did not calculate the percentages for food items because the intakes from the FFQ were expressed as categorical variables and could not be divided into thirds. 


\section{Results}

The male subjects were aged 45-77 years (mean \pm standard deviation (SD), $62.1 \pm 8.5$ years) and the female subjects $47-76$ years (mean $\pm \mathrm{SD}, 61.0 \pm 8.5$ years). Their major occupations were farmers, self-employed and housewives. The percentage of current smokers in men was $49.1 \%$ (27 subjects). No women currently smoked.

We observed significant seasonal differences in the consumption of carotene, ascorbic acid, fruits and vegetables. The daily consumption of carotene and ascorbic acid was high in November (3971 $\mu \mathrm{g}$ for carotene and $166 \mathrm{mg}$ for ascorbic acid in men; $3808 \mu \mathrm{g}$ for carotene and $186 \mathrm{mg}$ for ascorbic acid in women) and February (3418 $\mu \mathrm{g}$ and $128 \mathrm{mg} ; 3714 \mu \mathrm{g}$ and $141 \mathrm{mg}$, respectively) and low in May $(3150 \mu \mathrm{g}$ and $100 \mathrm{mg} ; 2995 \mu \mathrm{g}$ and $121 \mathrm{mg}$, respectively) and August (2827 $\mu \mathrm{g}$ and $100 \mathrm{mg} ; 3046 \mu \mathrm{g}$ and $116 \mathrm{mg}$, respectively). The daily consumption of fruits was high in November $(128.2 \mathrm{~g}$ in men and $143.0 \mathrm{~g}$ in women) and February (118.5 g and $150.2 \mathrm{~g}$, respectively) and low in May (86.9g and $113.7 \mathrm{~g}$, respectively) and August (62.4 g and $108.1 \mathrm{~g}$, respectively). Consumption of vegetables was high in November $(157.0 \mathrm{~g}$ in men and $163.0 \mathrm{~g}$ in women) and February $(154.9 \mathrm{~g}$ and $172.9 \mathrm{~g}$, respectively) and low in May (131.8g and $142.9 \mathrm{~g}$, respectively) and August (121.2 g and $133.7 \mathrm{~g}$, respectively). For other nutrients and food groups, we did not observe significant seasonal differences.

Table 1 presents the mean daily nutrient intakes in the DRs and FFQs, Spearman correlation coefficients between the DRs and the FFQs, and Spearman correlation coefficients between the two FFQs for both men and women. Compared with the DRs, the questionnaire underestimated the absolute amount of consumption for most of the nutrients except for retinol for both men and women. Adjusted and deattenuated Spearman correlation coefficients between the DRs and the FFQs ranged from 0.25 for protein to 0.58 for ascorbic acid in men and from 0.30 for retinol to 0.69 for phosphorus in women, with the median of 0.43 and 0.43 , respectively. Median (range) of Spearman correlation coefficients between the two FFQs administered at 1-year interval was 0.43 ( 0.31 for niacin to 0.71 for energy) in men and 0.43 ( 0.40 for protein and carbohydrates to 0.64 for riboflavin and ascorbic acid) in women.

Tables 2 and 3 present the mean daily consumption of 40 food items in the DRs and the FFQs, Spearman correlation coefficients between the DRs and the FFQs, and Spearman correlation coefficients between the two FFQs for men and women, respectively. Adjusted and deattenuated Spearman correlation coefficients for food intakes ranged from -0.30 for dried fish to 0.72 for milk in men and from -0.06 for fresh juice to 0.75 for pork in women, with a median of 0.35 and 0.34 , respectively. Median (range) of Spearman correlation coefficients administered at 1-year interval was 0.43 (0.14 for chicken to 0.76 for alcoholic beverages) in men and 0.45 ( 0.06 for deep-fried dishes to 0.74 for milk) in women.

Table 4 presents the mean daily consumption of nine food groups in the DRs and FFQs, Spearman correlation coefficients between the DRs and the FFQs, and Spearman correlation coefficients between the two FFQs for both men and women. Adjusted and deattenuated Spearman correlation coefficients for food groups intakes ranged from -0.10 for total meats to 0.76 for total fruits in men and from 0.28 for pulses to 0.70 for total fruits in women, with a median of 0.60 and 0.51 , respectively. Median (range) of the Spearman correlation coefficients administered at 1-year interval was 0.50 ( 0.30 for pulses to 0.70 for dairy products) in men and 0.57 ( 0.39 for yellow \& green vegetables to 0.66 for total meats) in women.

Tables 5 and 6 present agreement, adjacent agreement and complete disagreement percentages in the nutrient and food group intakes between the DRs and FFQ (crude and energy-adjusted). Median (range) of agreement percentages for energy-adjusted nutrient intakes was $43 \%$ (from $56 \%$ for ascorbic acid to $36 \%$ for sodium and riboflavin) in men and $47 \%$ (from $55 \%$ for phosphorus to $33 \%$ for retinol) in women. Median (range) of agreement percentages for energy-adjusted food group intakes was $53 \%$ (from $65 \%$ for dairy products to $33 \%$ for total meats) in men and 50\% (from 59\% for total fruits to $41 \%$ for total meats) in women. Median (range) of complete disagreement percentages for energy-adjusted nutrient intakes was $13 \%$ (from $15 \%$ for fat and thiamine to $4 \%$ for phosphorus) in men and $12 \%$ (from $17 \%$ for retinol to 3\% for calcium and phosphorus) in women. Median (range) of complete disagreement percentages with energy-adjusted food group intakes was $9 \%$ (from $25 \%$ for total meats to $4 \%$ for total fruits and vegetables) in men and 10\% (from 16\% for total vegetables excluding pickles to $5 \%$ for dairy products) in women.

\section{Discussion}

In this study, we assessed the validity and reproducibility of a 40-item FFQ used for two large-scale cohort studies among a rural Japanese population. The food lists in our questionnaire were not originally intended to calculate the consumption of nutrients. They were not selected for the questionnaire according to the cumulative contribution to absolute total nutrient intakes ${ }^{36}$ or the ability of the food items to discriminate between individual variations in nutrient intake ${ }^{37}$. Nevertheless, the questionnaire has a high reproducibility and a reasonably good validity for many nutrients in terms of correlation coefficients.

Median values of coefficients were almost the same between men and women in the nutrients, foods and food groups, but there were differences between sexes for several nutrients, foods and food groups. For example, regarding the validity for nutrients, there was a relatively large sex difference in correlations for energy ( 0.55 in men 


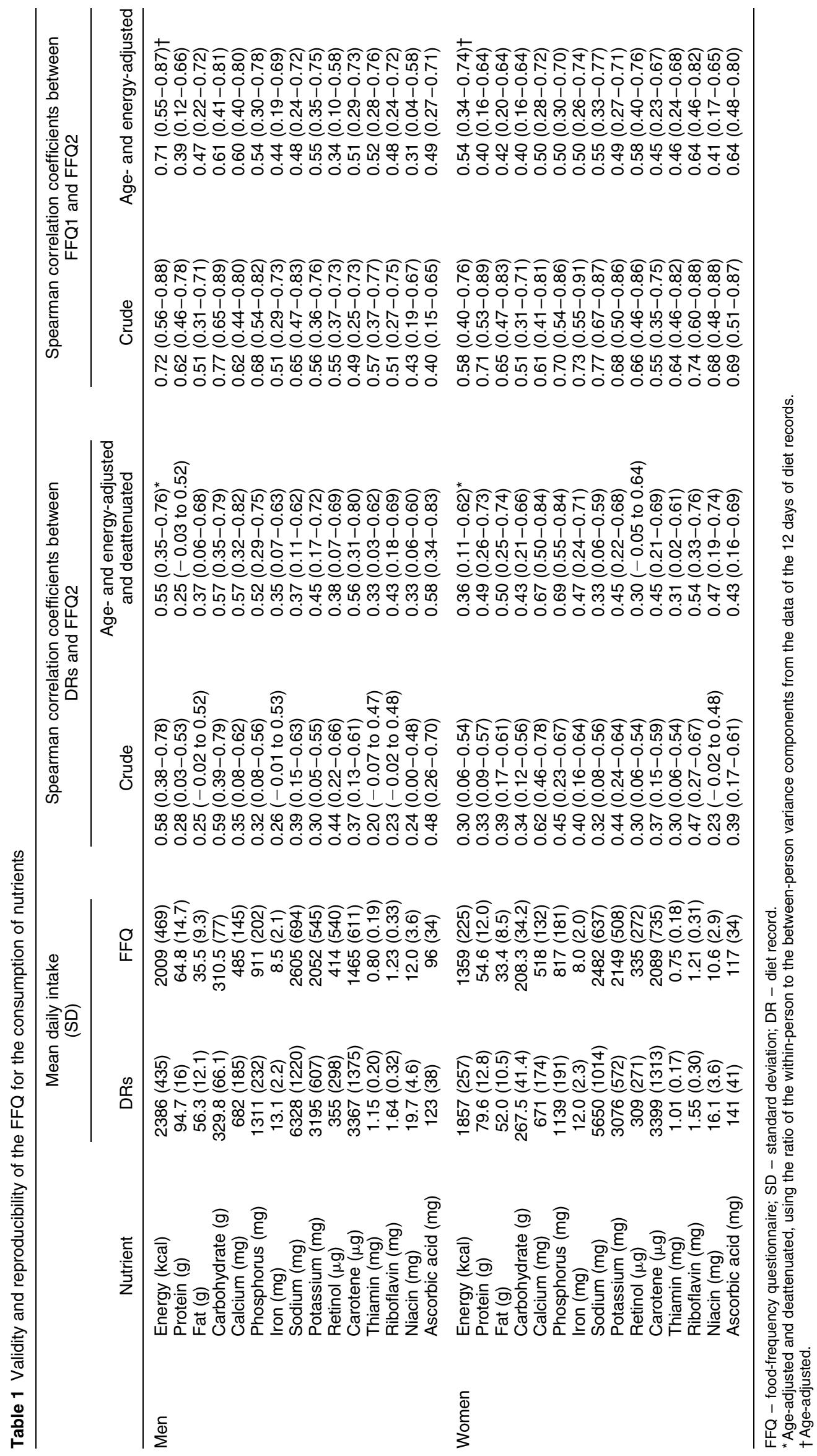




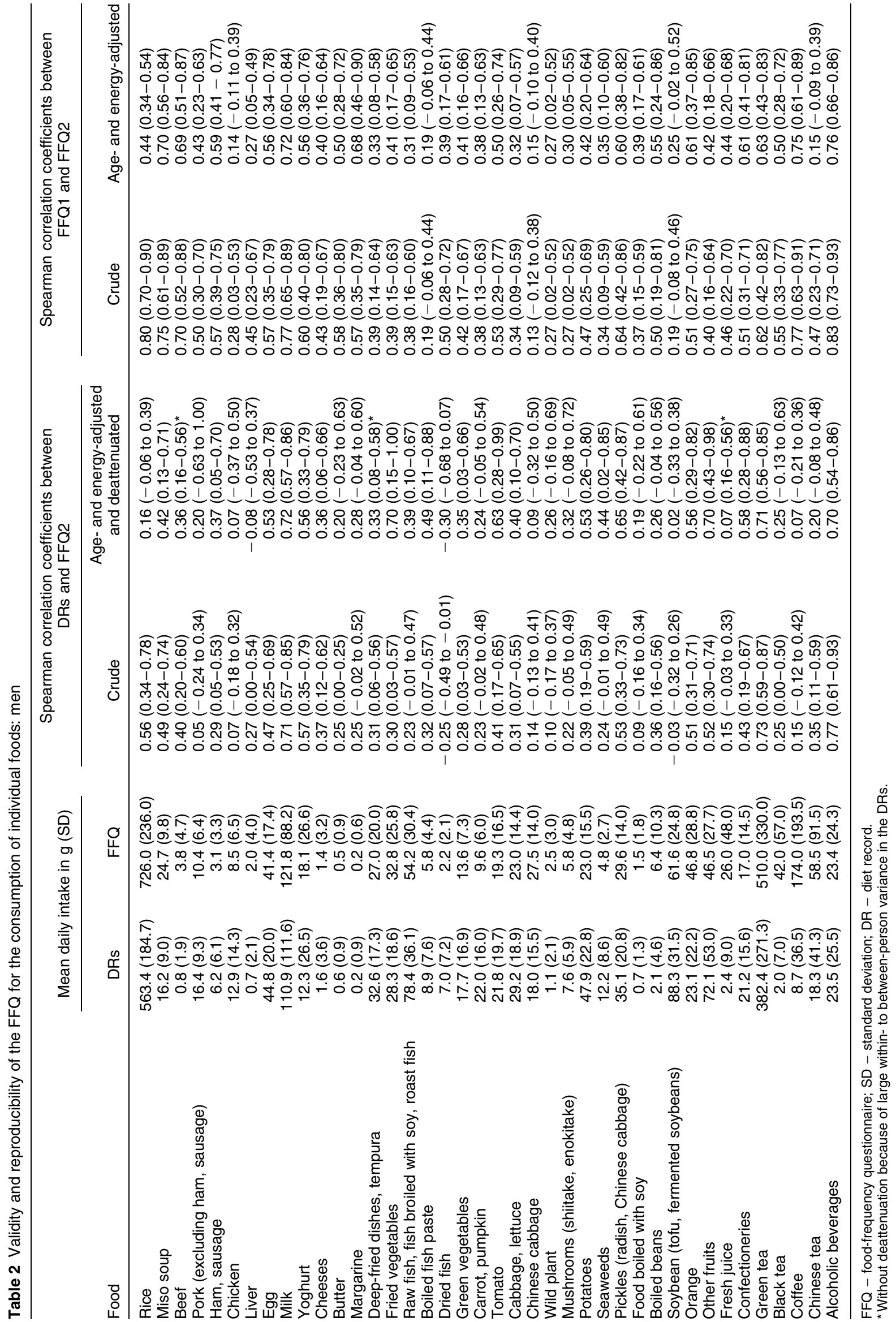




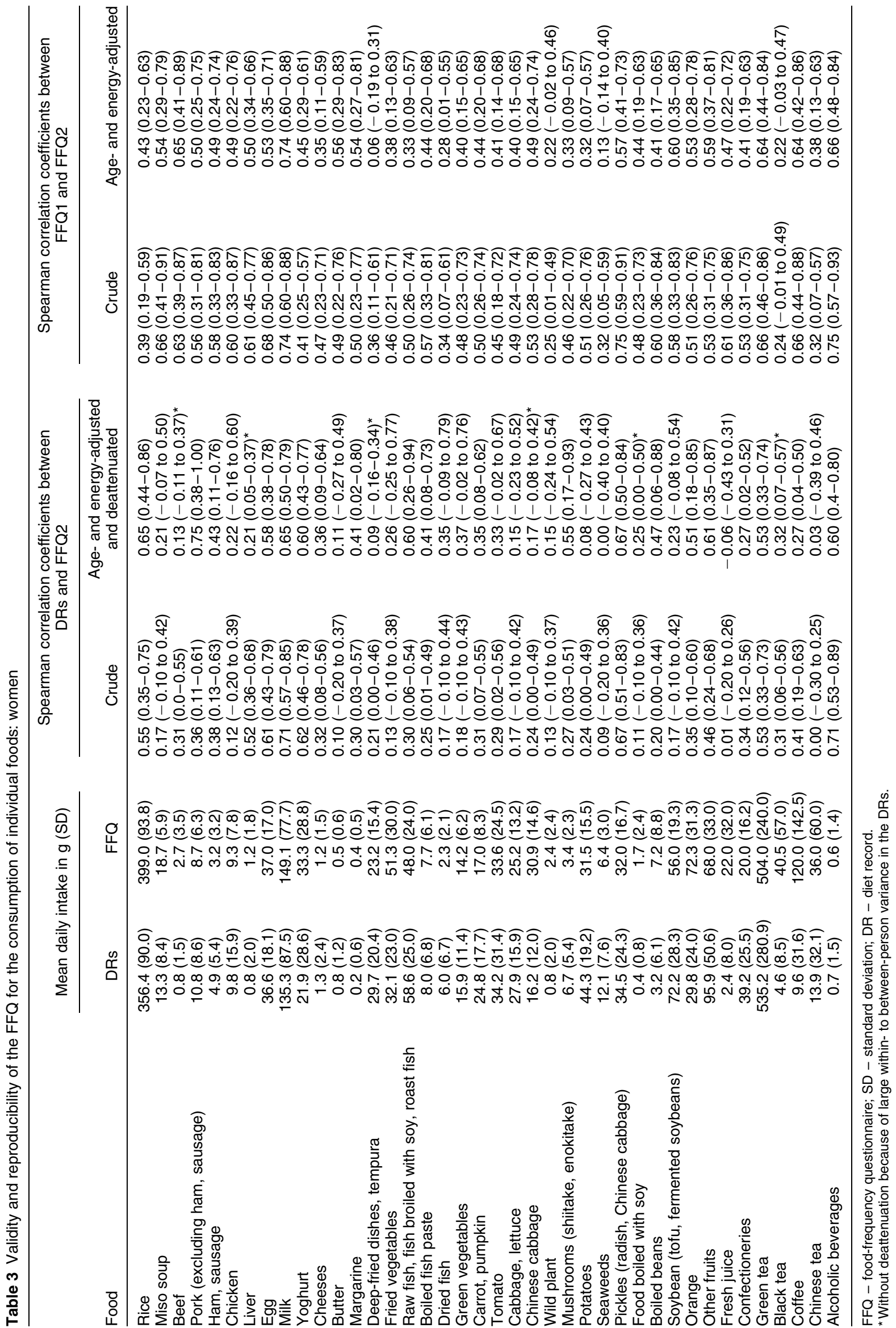




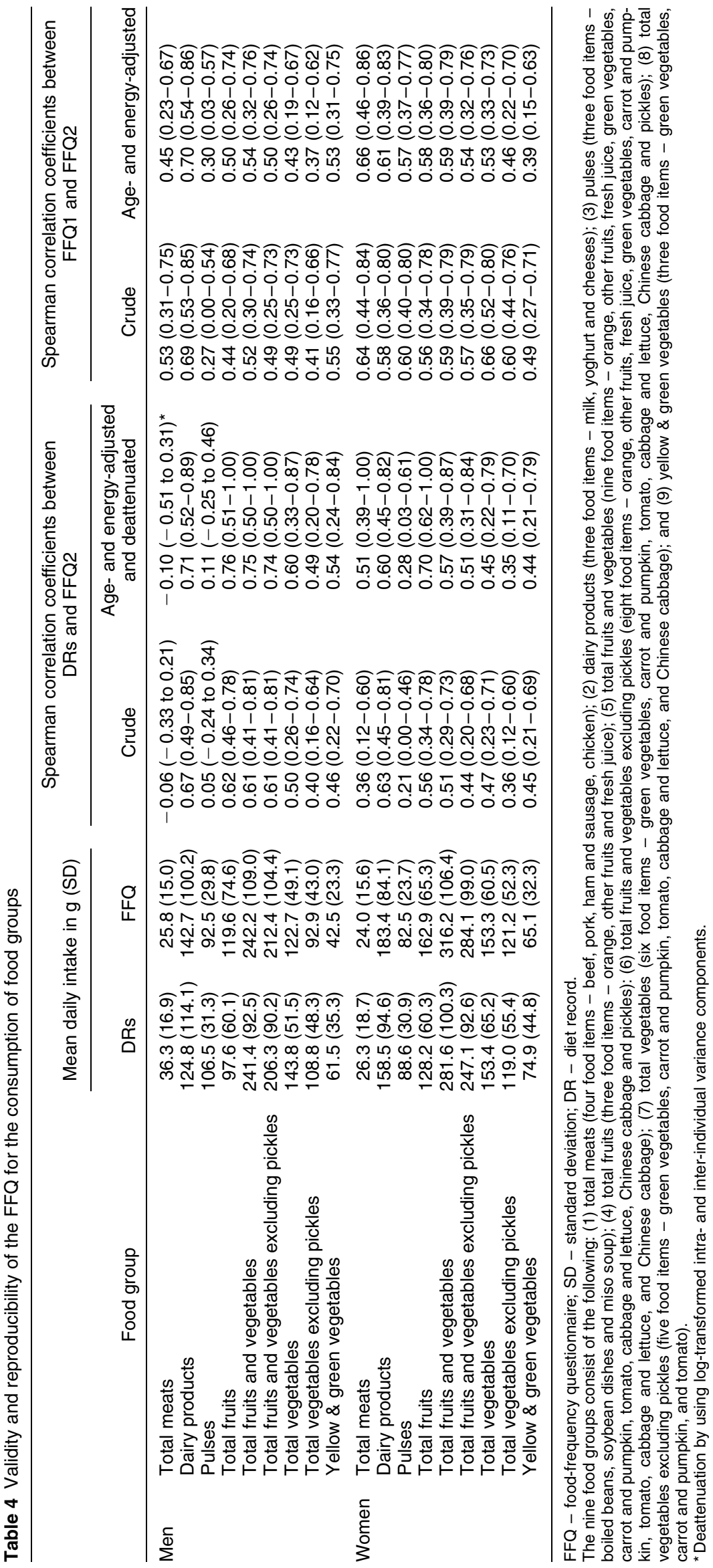


Table 5 Percentages of agreement, adjacent agreement and complete disagreement according to tertile classification of daily nutrient intakes based on the diet records and food-frequency questionnaire

\begin{tabular}{|c|c|c|c|c|c|c|c|}
\hline & \multirow[b]{2}{*}{ Nutrient } & \multicolumn{3}{|c|}{ Crude } & \multicolumn{3}{|c|}{ Energy-adjusted } \\
\hline & & $\begin{array}{c}\text { Agreement } \\
(\%)\end{array}$ & $\begin{array}{c}\text { Adjacent } \\
\text { agreement } \\
(\%)\end{array}$ & $\begin{array}{c}\text { Complete } \\
\text { disagreement } \\
(\%)\end{array}$ & $\begin{array}{c}\text { Agreement } \\
(\%)\end{array}$ & $\begin{array}{c}\text { Adjacent } \\
\text { agreement } \\
(\%)\end{array}$ & $\begin{array}{c}\text { Complete } \\
\text { disagreement } \\
(\%)\end{array}$ \\
\hline \multirow[t]{15}{*}{ Men } & Energy & 56 & 36 & 7 & - & - & - \\
\hline & Protein & 35 & 47 & 18 & 44 & 44 & 13 \\
\hline & Fat & 47 & 36 & 16 & 42 & 44 & 15 \\
\hline & Carbohydrate & 55 & 40 & 5 & 51 & 40 & 9 \\
\hline & Calcium & 55 & 33 & 13 & 47 & 42 & 11 \\
\hline & Phosphorus & 40 & 47 & 13 & 51 & 45 & 4 \\
\hline & Iron & 36 & 47 & 16 & 40 & 47 & 13 \\
\hline & Sodium & 42 & 47 & 11 & 36 & 53 & 11 \\
\hline & Potassium & 45 & 44 & 11 & 44 & 45 & 11 \\
\hline & Retinol & 42 & 51 & 7 & 49 & 38 & 13 \\
\hline & Carotene & 38 & 51 & 11 & 42 & 45 & 13 \\
\hline & Thiamin & 36 & 44 & 20 & 38 & 47 & 15 \\
\hline & Riboflavin & 36 & 45 & 18 & 36 & 51 & 13 \\
\hline & Niacin & 35 & 51 & 15 & 42 & 45 & 13 \\
\hline & Ascorbic acid & 53 & 36 & 11 & 56 & 36 & 7 \\
\hline \multirow[t]{15}{*}{ Women } & Energy & 40 & 45 & 16 & - & - & - \\
\hline & Protein & 43 & 45 & 12 & 47 & 40 & 14 \\
\hline & Fat & 45 & 41 & 14 & 50 & 41 & 9 \\
\hline & Carbohydrate & 47 & 45 & 9 & 52 & 36 & 12 \\
\hline & Calcium & 55 & 38 & 7 & 47 & 50 & 3 \\
\hline & Phosphorus & 43 & 48 & 9 & 55 & 41 & 3 \\
\hline & Iron & 47 & 45 & 9 & 48 & 41 & 10 \\
\hline & Sodium & 41 & 45 & 14 & 43 & 43 & 14 \\
\hline & Potassium & 48 & 41 & 10 & 40 & 52 & 9 \\
\hline & Retinol & 36 & 52 & 12 & 33 & 50 & 17 \\
\hline & Carotene & 36 & 48 & 16 & 43 & 45 & 12 \\
\hline & Thiamin & 36 & 50 & 14 & 48 & 36 & 16 \\
\hline & Riboflavin & 48 & 41 & 10 & 50 & 38 & 12 \\
\hline & Niacin & 45 & 40 & 16 & 53 & 31 & 16 \\
\hline & Ascorbic acid & 38 & 48 & 14 & 45 & 41 & 14 \\
\hline
\end{tabular}

Table 6 Percentages of agreement, adjacent agreement and complete disagreement according to tertile classification of daily intakes of food groups based on the diet records and food-frequency questionnaire

\begin{tabular}{|c|c|c|c|c|c|c|c|}
\hline & \multirow[b]{2}{*}{ Food group } & \multicolumn{3}{|c|}{ Crude } & \multicolumn{3}{|c|}{ Energy-adjusted } \\
\hline & & $\begin{array}{l}\text { Agreement } \\
(\%)\end{array}$ & $\begin{array}{l}\text { Adjacent } \\
\text { agreement } \\
(\%)\end{array}$ & $\begin{array}{c}\text { Complete } \\
\text { disagreement } \\
(\%)\end{array}$ & $\begin{array}{l}\text { Agreement } \\
(\%)\end{array}$ & $\begin{array}{l}\text { Adjacent } \\
\text { agreement } \\
(\%)\end{array}$ & $\begin{array}{c}\text { Complete } \\
\text { disagreement } \\
(\%)\end{array}$ \\
\hline \multirow{9}{*}{ Men } & Total meats & 38 & 33 & 29 & 33 & 42 & 25 \\
\hline & Dairy products & 65 & 29 & 5 & 65 & 29 & 5 \\
\hline & Pulses & 35 & 45 & 20 & 38 & 38 & 24 \\
\hline & Total fruits & 53 & 44 & 4 & 56 & 35 & 9 \\
\hline & Total fruits and vegetables & 64 & 31 & 5 & 60 & 36 & 4 \\
\hline & Total fruits and vegetables excluding pickles & 58 & 35 & 7 & 58 & 35 & 7 \\
\hline & Total vegetables & 60 & 29 & 11 & 53 & 38 & 9 \\
\hline & Total vegetables excluding pickles & 49 & 36 & 15 & 51 & 38 & 11 \\
\hline & Yellow \& green vegetables & 45 & 45 & 9 & 47 & 40 & 13 \\
\hline \multirow[t]{9}{*}{ Women } & Total meats & 47 & 38 & 16 & 41 & 45 & 14 \\
\hline & Dairy products & 60 & 34 & 5 & 57 & 38 & 5 \\
\hline & Pulses & 34 & 48 & 17 & 52 & 38 & 10 \\
\hline & Total fruits & 55 & 33 & 12 & 59 & 33 & 9 \\
\hline & Total fruits and vegetables & 48 & 45 & 7 & 50 & 40 & 10 \\
\hline & Total fruits and vegetables excluding pickles & 53 & 34 & 12 & 48 & 34 & 17 \\
\hline & Total vegetables & 59 & 28 & 14 & 48 & 40 & 12 \\
\hline & Total vegetables excluding pickles & 52 & 33 & 16 & 48 & 36 & 16 \\
\hline & Yellow \& green vegetables & 48 & 41 & 10 & 52 & 38 & 10 \\
\hline
\end{tabular}


and 0.36 in women) and protein (0.25 and 0.49, respectively).

The absolute mean levels of consumption for energy and most nutrients were lower in our questionnaire than in the diet records. This is probably due to the relatively small number of food items included in our questionnaire. A questionnaire with a larger number of food items may better estimate the absolute amount of food and nutrient consumption. In contrast, the absolute consumption levels for individual food items were not necessarily lower in our questionnaire than in the diet records, which would indicate that the validity of our questionnaire in assessing the absolute amount of intake varies by food item. However, the problem of our questionnaire estimates of absolute intake should be of less concern when they are applied to the main cohort studies, since we would use energy-adjusted values rather than absolute values, and the primary objective of analyses would be to rank individuals within the cohorts according to the relative levels of consumption.

Table 7 summarises studies conducted in Japan examining the validity and reproducibility of FFQs in assessing the consumption of multiple nutrients. Among these studies, median correlation coefficients between the DRs and the FFQs ranged from 0.36 to 0.61 , and median reproducibility between the FFQs ranged from 0.32 to 0.72 . Our questionnaire showed validity and reproducibility comparable with those reported in other Japanese studies.

The validity and reproducibility of individual food items $^{27,28}$ and dietary patterns ${ }^{38}$ in the FFQ were examined for the US population. For the Japanese population, Wakai et al. $^{29}$ examined the validity and reproducibility of 20 food group intakes assessed by a 97-item FFQ. Median (range) of correlation coefficients with the DRs was 0.56 ( 0.16 for noodles to 0.83 for milk and dairy products). Median (range) of correlation coefficients for 1-year reproducibility was 0.54 ( 0.34 for eggs to 0.78 for breads). Tokudome et al $^{11}$ also examined the validity of 15 food group intakes assessed by a 102-item FFQ. Median (range) of correlation coefficients with the DRs was 0.52 ( 0.17 for beverages to 0.83 for rice). Our results are similar to the findings in these studies.

Regarding the nutrients and food groups with high correlation coefficients, agreement and complete disagreement percentages according to tertile classification of daily intakes based on DRs and FFQ were generally high and low, respectively, in our study. The agreement and complete disagreement percentages of ascorbic acid in men (Spearman correlation coefficient, 0.58) were 56\% and $7 \%$ (energy-adjusted), respectively. In contrast, the agreement and complete disagreement percentages of retinol in women (Spearman correlation coefficient, 0.30) were $33 \%$ and $17 \%$ (energy-adjusted), respectively. Because we cannot assume that the two variables (daily intake from DR and daily intake from FFQ) are normally distributed and their relationship is linear, we calculated

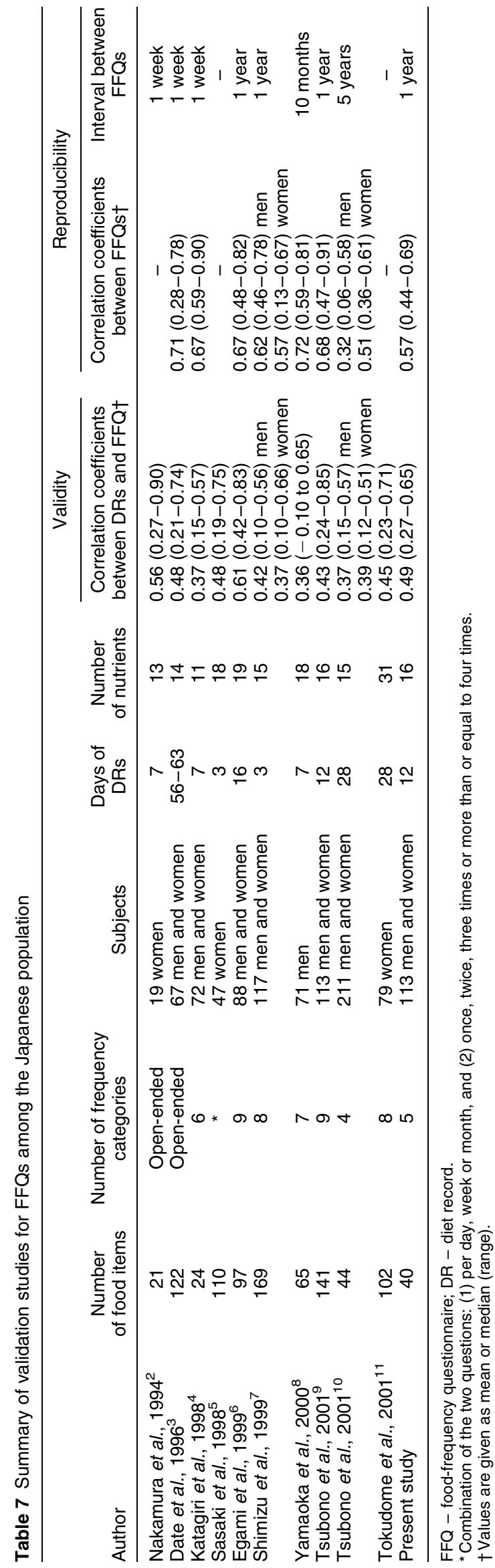


agreement and complete disagreement percentages to ascertain the usefulness of the FFQ for dividing individuals according to their level of consumption.

For interpreting the results presented in Tables 5 and 6, we must consider what would be expected by chance alone. For example, the probability of agreement and complete disagreement expected by chance alone in tertile classification is 33\% and 22\%, respectively. Thus, we might have overestimated agreement percentages or underestimated complete disagreement percentages.

Some traditional Japanese foods, such as green tea and soybean products (tofu, miso, etc.), have recently drawn attention as being potentially health-protective. Although many studies have been conducted in Japan to examine the associations between consumption of green tea ${ }^{19-22}$, soy products ${ }^{23-26}$ and various health outcomes, most studies did not document the validity and reproducibility of questionnaires used to measure the usual consumption of these food items. In this study, the correlation between our questionnaire and the DRs was high for green tea (adjusted and deattenuated Spearman correlation coefficient of 0.71 in men and 0.53 in women), moderate for miso soup ( 0.42 and 0.21 , respectively) and low for soybean products ( 0.02 and 0.23 , respectively). These results suggest that the validity of FFQs for Japanese populations may vary by the food item examined.

A possible reason for the low correlation for soybean products may be the lack of variation in the questionnaire responses owing to a limited number of frequency categories, since the majority of men (65.5\%) and women (75.9\%) chose the highest category (almost daily). A questionnaire with a larger number of frequency categories at the high end may have improved validity for the assessment of soybean intake. Another reason may be the lack of between-person variation in our subjects in the actual consumption of soybeans. The ratio of between- to within-person variation in soybean intake, estimated from the diet record data, was 5.92 in men and 5.52 in women. These ratios are relatively higher compared with other popular foods such as rice (0.69 and 1.18 , respectively), miso soup (3.50 and 3.14, respectively) and green tea (0.99 and 1.20 , respectively), indicating the relatively limited between-person variation for intake of soy foods.

We have reported that consumption of green tea, as measured by another FFQ with high validity, is not associated with decreased risk of gastric cancer in a different cohort study conducted in the same area ${ }^{13}$. Using the two cohort studies in which the present FFQ is used, we are currently examining the associations between green tea, soybean products and various cancers. We are also beginning to examine the relationship between level of intake of food groups such as fruit and vegetables and cancer risk at several sites, because we can show that our FFQ is useful to divide individuals according to their relative level of intake.
Information regarding validity is important and indispensable in interpreting study results ${ }^{1}$. For example, when a calculated relative risk suggests 'no association' between diet and diseases, it may come from too small correlations between the DR and FFQ to detect differences between dietary exposures. Dietary exposures are often expressed in quintiles. Our results suggest that gross misclassification exists in several nutrients or food groups calculated by our FFQ. The attenuation of relative risks towards the null hypothesis can be caused by this non-differential misclassification $^{39}$.

In summary, we examined the validity and reproducibility of a 40-item FFQ used for two prospective cohort studies in rural Japan. Our results indicate comparable validity and reproducibility with regard to the consumption of nutrients, foods and food groups. This brief FFQ is useful to examine the association between diet and health in the Japanese population.

\section{Acknowledgements}

This study was supported in part by Grants-in-Aid for Scientific Research from the Ministry of Education, Science, Sports and Culture (09470106) and by Health Sciences Research Grants for Research on Health Services (H10-25) from the Ministry of Health and Welfare in Japan.

\section{References}

1 Willett WC. Nutritional Epidemiology, 2nd ed. Oxford: Oxford University Press, 1998.

2 Nakamura M, Aoki N, Nasu K, Kondo I. A comparison between a food frequency and amount questionnaire and 7-day diet record with weighing. Jpn. J. Public Health 1994; 41: 682-92 [in Japanese].

3 Date C, Yamaguchi M, Tanaka H. Development of a food frequency questionnaire in Japan. J. Epidemiol. 1996; 6(Suppl.): 131-6.

4 Katagiri A, Hashimoto S, Ohashi Y, Shirogane K, Sakamoto $\mathrm{N}$, Makimoto S. Reproducibility and validity of a semiquantitative food frequency questionnaire. Jpn. J. Public Health 1998; 45: 1127-36 [in Japanese].

5 Sasaki S, Yanagibori R, Amano K. Self-administered diet history questionnaire development of health education: a relative validation of the test version by comparison with 3-day diet record in women. J. Epidemiol. 1998; 8 203-15.

6 Egami I, Wakai K, Kato K, Lin Y, Kawamura T, Tamakoshi A, et al. A simple food frequency questionnaire for Japanese diet - Part II. Reproducibility and validity for nutrient intakes. J. Epidemiol. 1999; 9: 227-34.

7 Shimizu H, Ohwaki A, Kurisu Y, Takatsuka N, Ido M, Kawasaki $\mathrm{N}$, et al. Validity and reproducibility of a quantitative food frequency questionnaire for a cohort study in Japan. Jpn. J. Clin. Oncol. 1999; 29: 38-44.

8 Yamaoka K, Tango T, Watanabe M, Tokotsuka M. Validity and reproducibility of a semi-quantitative food frequency questionnaire for nutritional education of patients of diabetes mellitus (FFQW65). Jpn. J. Public Health 2000; 47: 230-44 [in Japanese].

9 Tsubono Y, Sasaki S, Kobayashi M, Akabane M, Tsugane S. Food composition and empirical weight methods in 
predicting nutrient intakes from food frequency questionnaire. Ann. Epidemiol. 2001; 11: 213-8.

10 Tsubono Y, Ogawa K, Watanabe Y, Nishino Y, Tsuji I, Watanabe $\mathrm{T}$, et al. Food frequency questionnaire as a screening test. Nutr. Cancer 2001; 39(1): 78-84.

11 Tokudome S, Imaeda N, Tokudome Y, Fujiwara N, Nagaya T, Sato J, et al. Relative validity of a semi-quantitative food frequency questionnaire versus 28 day weighed diet records in Japanese female dietitians. Eur. J. Clin. Nutr. 2001; 55: $735-42$.

12 Hu FB, Stampfer MJ, Rimm EB, Manson JE, Ascherio A, Colditz GA, et al. A prospective study of egg consumption and risk of cardiovascular disease in men and women. J. Am. Med. Assoc. 1999; 281: 1387-94.

13 Tsubono Y, Nishino Y, Komatsu S, Hsieh CC, Kanemura S, Tsuji I, et al. Green tea and the risk of gastric cancer in Japan. N. Engl. J. Med. 2001; 344: 632-6.

14 Feskanich D, Ziegler RG, Michaud DS, Giovannucci EL, Speizer FE, Willett WC, et al. Prospective study of fruit and vegetable consumption and risk of lung cancer among men and women. J. Natl. Cancer Inst. 2000; 92: 1812-23.

$15 \mathrm{Hu}$ FB, Rimm E, Stampfer MJ, Ascherio A, Spiegelman D, Willett WC. Prospective study of major dietary patterns and risk of coronary heart disease in men. Am.J. Clin. Nutr. 2000; 72(4): 912-21.

16 Michels KB, Giovannucci EL, Joshipura KJ, Rosner BA, Stampfer MJ, Fuchs CS, et al. Prospective study of fruit and vegetable consumption and incidence of colon and rectal cancers. J. Natl. Cancer Inst. 2000; 92: 1740-52.

17 Smith-Warner SA, Spiegelman D, Yaun SS, Adami HO, Beeson WL, van den Brandt PA, et al. Intake of fruits and vegetables and risk of breast cancer - a pooled analysis of cohort studies. J. Am. Med. Assoc. 2001; 285: 769-76.

18 Terry P, Giovannucci EL, Michels KB, Bergkvist L, Hansen H, Holmberg L, et al. Fruit, vegetables, dietary fiber, and risk of colorectal cancer. J. Natl. Cancer Inst. 2001; 93: 525-33.

19 Imai K, Suga K, Nakachi K. Cancer-preventive effects of drinking green tea among a Japanese population. Prev. Med. 1997; 26(6): 769-75.

20 Inoue $\mathrm{M}$, Tajima $\mathrm{K}$, Hirose $\mathrm{K}$, Hamajima $\mathrm{N}$, Takezaki $\mathrm{T}$, Kuroishi T, et al. Tea and coffee consumption and the risk of digestive tract cancers: data from a comparative casereferent study in Japan. Cancer Causes Control 1998; 9: 209-16.

21 Kono S, Ikeda M, Tokudome S, Kuratsune M. A case-control study of gastric cancer and diet in northern Kyushu, Japan Jpn. J. Cancer Res. 1988; 79: 1067-74.

22 Tajima K, Tominaga S. Dietary habits and gastro-intestinal cancer: a comparative case-control study of stomach and large intestinal cancers in Nagoya, Japan. Jpn. J. Cancer Res. 1985; 76: 705-16.

23 Horiuchi T, Onouchi T, Takahashi M, Ito H, Orimo H. Effect of soy protein on bone metabolism in postmenopausal Japanese women. Osteoporosis Int. 2000; 11(8): 721-4.

24 Nagata C, Takatsuka N, Kawakami N, Shimizu H. Soy product intake and hot flashes in Japanese women: results from a community-based prospective study. $\mathrm{Am}$. J. Epidemiol. 2001; 153(8): 790-3.
25 Sasazuki S. Case-control study of nonfatal myocardial infarction in relation to selected foods in Japanese men and women. Fukuoka Heart Study Group. Jpn. Cir. J. 2001; 65(3): 200-6.

26 Somekawa Y, Chiguchi M, Ishibashi T, Aso T. Soy intake related to menopausal symptoms, serum lipids, and bone mineral density in postmenopausal Japanese women. Obstet. Gynecol. 2001; 97(1): 109-15.

27 Salvini S, Hunter DJ, Sampson L, Stampfer MJ, Colditz GA, Rosner $\mathrm{B}$, et al. Food-based validation of a dietary questionnaire: the effects of week-to-week variation in food consumption. Int. J. Epidemiol. 1989; 18: 858-67.

28 Feskanich D, Rimm EB, Giovannucci EL, Colditz GA, Stampfer MJ, Litin LB, et al. Reproducibility and validity of food frequency questionnaire. J. Am. Diet Assoc. 1993; 93: $790-6$.

29 Wakai K, Egami I, Kato K, Lin Y, Kawamura T, Tamakoshi A, et al. A simple food frequency questionnaire for Japanese diet - Part I. Reproducibility and validity for nutrient intakes. J. Epidemiol. 1999; 9: 227-34.

30 Fukao A, Tsubono Y, Komatsu S, Tsuji I, Minami Y, Hisamichi S, et al. A cohort study on the relation of lifestyle, personality and biologic markers to cancer in Miyagi, Japan: study design, response rate and profiles of the cohort subjects. J. Epidemiol. 1995; 5: 153-7.

31 Tsuji I, Nishino Y, Ohkubo Tuwahara A, Ogawa K, Watanabe $\mathrm{Y}$, Tsubono Y, et al. A prospective cohort study on national health insurance beneficiaries in Ohsaki, Miyagi Prefecture, Japan: study design, profiles of the subjects and medical cost during the first year. J. Epidemiol. 1998; 8: 258-63.

32 Ohno Y, Tamakoshi A. Japan collaborative cohort study for evaluation of cancer risk sponsored by Monbusho (JACC study). The JACC Study Group. J. Epidemiol. 2001; 11: $144-50$.

33 Science and Technology Agency. Standard Tables of Food Composition in Japan, 4th revised ed. Tokyo: Printing Bureau, Ministry of Finance, 1982 [in Japanese].

34 Willett WC, Stampfer MJ. Total energy intake: implications for epidemiologic analyses. Am. J. Epidemiol. 1986; 124: $17-27$.

35 Rosner B, Willett WC. Interval estimates for correlation coefficients corrected for within-person variation: implications for study design and hypothesis testing. Am. J. Epidemiol. 1988; 127: 377-86.

36 Block G, Hartman AM, Dresser CM, Carroll MD, Gannon J, Gardner L. A data-based approach to diet questionnaire design and testing. Am. J. Epidemiol. 1986; 124: 453-69.

37 Willett WC, Sampson L, Stampfer MJ, Rosner B, Bain C, Witschi $\mathrm{J}$, et al. Reproducibility and validity of a semiquantitative food-frequency questionnaire. $\mathrm{Am}$. J. Epidemiol. 1985; 122: 51-65.

38 Hu FB, Rimm E, Smith-Warner SA, Feskanich D, Stampfer MJ, Ascherio A, et al. Reproducibility and validity of dietary patterns assessed with a food-frequency questionnaire. Am. J. Clin. Nutr. 1999; 69(2): 243-9.

39 Armstrong BK, White E, Saracci R. Principles of Exposure Measurement in Epidemiology. Oxford: Oxford University Press, 1992. 